\title{
Simultaneous growth, survival and death: The trimodal behavior of Salmonella cells under osmotic stress giving rise to "Phoenix phenomenon"
}

\author{
Zafiro Aspridou, Theodora Akritidou, Konstantinos P. Koutsoumanis* \\ Laboratory of Food Microbiology and Hygiene, Department of Food Science and Technology, School of Agriculture, Forestry and Natural Environment, Aristotle University \\ of Thessaloniki, Thessaloniki 54124, Greece
}

\section{A R T I C L E I N F O}

\section{Keywords:}

Salmonella

Osmotic stress

Growth

Death

Phoenix phenomenon

\begin{abstract}
A B S T R A C T
Time-lapse microscopy methods were used to monitor growth, survival and death of Salmonella enterica serotype Agona individual cells on solid laboratory medium (tryptone soy agar) in the presence of various salt concentrations $(0.5 \%, 3.5 \%, 4.5 \%$ and $5.7 \% \mathrm{NaCl})$. The results showed a highly heterogeneous behavior. $\mathrm{As} \mathrm{NaCl}$ concentration increased, the distribution of the first division time was shifted to higher values and became wider. The mean first division time increased from $1.8 \mathrm{~h}$ at $0.5 \% \mathrm{NaCl}$ to $5.48 \mathrm{~h}, 16.2 \mathrm{~h}$, and $35.9 \mathrm{~h}$ at $3.5 \%, 4.5 \%$ and $5.7 \% \mathrm{NaCl}$, respectively. The concentration of $\mathrm{NaCl}$ in the growth medium also affected the ability of the cells to divide. The percentage of cells able to grow decreased from $88.9 \%$ at $0.5 \% \mathrm{NaCl}$ to $66.5 \%, 32.8 \%$, and $6.9 \%$ at $3.5 \%, 4.5 \%$ and $5.7 \% \mathrm{NaCl}$, respectively. In the latter case $(5.7 \% \mathrm{NaCl}), 74$ cells out of 406 cells tested $(18 \%)$ died with mean time to death $5.03 \mathrm{~h}$ and standard deviation $6.70 \mathrm{~h}$. To investigate the effect of the behavior of individual cells on the dynamics of the whole population, simulation analysis was used. The simulation results showed that the simultaneous growth, survival and death of cells observed under osmotic stress can lead to a total population behavior known as the "Phoenix" phenomenon. The simulation findings were confirmed by validation experiments using both viable counts and time lapse microscopy. The results of the present study show the high heterogeneity of individual cell responses and the complexity in the behavior of microbial populations at conditions approaching the boundaries of growth.
\end{abstract}

\section{Introduction}

Most of the models in Predictive Microbiology are based on simplicity and reductionism describing the behavioral output of microbial populations as a whole in response to environment ignoring microbial individuality. Extensive validation studies in various foods have shown that, although deterministic population models are generally valid for predicting microbial behavior at optimal or suboptimal environmental conditions, they present a very low performance in the case of more stressful and complex environments close to the boundary of growth (Koutsoumanis et al., 2016; Koutsoumanis and Aspridou, 2016). This can be attributed to the highly heterogeneous behavior of bacterial cells at such conditions due to the stochastic variations associated with the genomic information flow including gene activation, transcription and translation (Avery, 2006).

Recent studies on microbial behavior at conditions close to the boundaries of growth have shown a significant heterogeneity in the ability of individual cells to initiate growth (Aguirre and Koutsoumanis, 2016; Koutsoumanis, 2008). Koutsoumanis (2008) studied the growth limits of Salmonella Enteritidis individual cells exposed to osmotic stress and reported that as the $\mathrm{NaCl}$ concentration increases, the number of the cells in the population able to grow gradually decreases. Aguirre and Koutsoumanis (2016) confirmed the above findings for heat treated and non-treated cells of Listeria monocytogenes. Both studies showed that the bistable behavior of individual cells (growth/no growth) under osmotic stress leads to an additional lag in the population growth (called "pseudo-lag") with the total apparent lag of the population being the sum of the physiological lag of the growing cells (time required to adjust to the new environment) and the pseudo-lag induced by the presence of the non-growing cells.

Other studies on microbial behavior at more severe osmotic conditions showed that cells can initially display some loss of viability, but some survivors eventually initiate growth (Mellefont et al., 2005; Zhou et al., 2011). In this case the viable count growth curve exhibits a decrease after inoculation followed by a period in which numbers remain unchanged and, thereafter, exponential growth ensues. The latter has been termed as "Phoenix phenomenon" firstly reported by Collee et al. (1961). Later, Shoemaker and Pierson (1976) studied the "Phoenix

\footnotetext{
* Corresponding author.

E-mail address: kkoutsou@agro.auth.gr (K.P. Koutsoumanis).
} 
phenomenon" in the growth of Clostridium perfringens and came to the conclusion that it involves three phases: injury, recovery and growth. In contrast, Mellefont et al. (2005) stated that the phenomenon is due to an initial inactivation of a portion of the population followed by growth, rather than injury and recovery of the ability to form colonies on the enumeration medium. However, the above studies as well as all available data about the "Phoenix phenomenon" are based on population level experimentations without studying the behavior of individual cells. To determine whether the subsequent increase in viable counts is due to recovery of culturability of a relatively large fraction of the population, or due to growth within a relatively small fraction of survivors, would require clear discrimination and monitoring of the individual cells within the population.

Recent technological advances enable the study of microbial behavior at the single cell level. Methods based on microscopy and image analysis have been developed and employed for monitoring multiple single cell generations and colonial growth of single cells (Elfwing et al., 2004; Koutsoumanis and Lianou, 2013). Such technologies are expected to be able to differentiate individual cell responses within a population and unravel the underlying mechanisms of microbial behavior under stressful conditions.

For Salmonella cells, several studies have reported that as the concentration of sodium chloride increases over $0.5 \%$ towards $7-8 \%$, the environmental conditions start to deviate from the optimum towards the growth boundaries (Koutsoumanis, 2008; Zhou et al., 2011). The objectives of the present work were a) to use time lapse microscopy methodologies in order to monitor division and death of Salmonella single cells during exposure under various indicative concentrations of sodium chloride within the range of 0.5 to $7 \%$ and $b$ ) to investigate the role of individual cell heterogeneity in the behavior of microbial populations at conditions close to the boundary of growth.

\section{Materials and methods}

\subsection{Bacterial strain}

The bacterial strain used in this study was a Salmonella enterica serotype Agona animal isolate, kindly provided by Dr. Martin Wiedmann (Cornell University, New York, United States of America). Stock cultures of the strain were kept frozen $\left(-70^{\circ} \mathrm{C}\right)$ onto Microbank TM porous beads (Pro-Lab Diagnostics, Ontario, Canada), while working cultures were stored refrigerated $\left(5^{\circ} \mathrm{C}\right)$ on tryptone soy agar (TSA; Lab M Limited, Lancashire, United Kingdom) slants and were renewed bimonthly.

\subsection{Study of individual cell behavior}

The behavior of the pathogen in the presence of various concentrations of sodium chloride was studied at the single cell level through time lapse microscopy and at the population level using plate count. Single cell division times and individual cell times of inactivation were monitored by phase-contrast and confocal laser scanning microscopy, respectively. Due to the microscope setup, the optimum temperature of $37^{\circ} \mathrm{C}$ for the long duration of the experiments was a limiting factor. The selected temperature, close to the environmental one, is favorable for Salmonella growth and slightly longer division times than at optimum conditions are expected.

\subsubsection{Monitoring single cell division times}

Single cell growth behavior was studied, under various concentrations of sodium chloride ( $\mathrm{NaCl} 0.5,3.5,4.5$ and $5.7 \% \mathrm{w} / \mathrm{w})$, on solid laboratory medium (TSA) at $27^{\circ} \mathrm{C}$. These concentrations were achieved by adding appropriate amounts of salt to the medium which already contains $5 \mathrm{~g} / 1$ of sodium chloride. The water activity values of the media were measured with an Aqualab water activity meter (Model series 3; Decagon Devices, Inc., Pullman, United States of America) and were the following: $0.995(0.5 \% \mathrm{NaCl}), 0.977(3.5 \% \mathrm{NaCl}), 0.973(4.5 \%$ $\mathrm{NaCl})$ and $0.957(5.7 \% \mathrm{NaCl})$.

The strain was activated by transferring a loopful from TSA slants into $10 \mathrm{ml}$ of tryptone soy broth without dextrose (TSB-G; Lab M Limited) and incubating at $37^{\circ} \mathrm{C}$ for $18 \mathrm{~h}$. An aliquot of $100 \mu \mathrm{l}$ of the 18 $\mathrm{h}$ culture, after appropriate serial decimal dilutions in one-quarterstrength Ringer's solution (Lab M Limited), with a target population of $10^{7} \mathrm{cfu}$ was surface plated on $8 \mathrm{ml}$ TSA (with appropriate amount of $\mathrm{NaCl}$ added) solidified in a $90 \mathrm{~mm}$ Petri dish. The inoculated agar was left to dry in a biological safety cabinet for $3 \mathrm{~min}$ and, then, a piece (approximately $20 * 20 \mathrm{~mm}$ ) was removed with a scalpel and placed on a glass slide $(25 * 75 \mathrm{~mm}$, thickness $1-1.2 \mathrm{~mm})$. The piece of agar was covered by a coverslip and sealed with silicone to avoid dehydration.

Cell division and growth was monitored by phase-contrast time lapse microscopy using a z-motorized microscope (Olympus BX61, Olympus, Tokyo, Japan) equipped with a $100 \times$ objective (Olympus) and a high-resolution device camera (Olympus DP71). The sample was maintained at $27^{\circ} \mathrm{C}$ using a temperature controlled stage (Linkam PE60, Linkam Scientific Instruments, Surrey, United Kingdom). Images of the field of view were acquired every $5 \mathrm{~min}$ for 24 to $72 \mathrm{~h}$. Three to five independent experiments were conducted in order to collect data for approximately 400 cells under each $\mathrm{NaCl}$ concentration. An inhouse program with the ScopePro module of the ImageProPlus image analysis software version 6.3 (MediaCybernetics Inc. Bethesda, United States of America) was used, which allows the system to be automatically turned on and off before and after the capture of an image. The quality of the images was improved by the autofocus procedure with an extended depth of focus (EDF) system. This procedure allows for multiple (20 to 30 ) serial images in different $\mathrm{z}$-axis planes to be captured and, then, combines the best focal areas of the serial images into a single in-focus image (z-stack). Individual stack images were compiled and transformed into a time-lapse video showing the behavior of the single cells of the pathogen. Image analysis was performed using the ImageProPlus image analysis software. The high quality of the images allowed the monitoring of division times and the number of cells in the micro-colonies. The manual tag of the software was employed for cell counting. Data about the percentage of dividing and nondividing cells, first and second division times, cell lysis and filamentation were collected.

\subsubsection{Monitoring individual cell times of inactivation}

Single cell inactivation behavior was studied in the presence of 5.1 and $5.7 \%(\mathrm{w} / \mathrm{w})$ sodium chloride on solid laboratory medium (TSA) at $27^{\circ} \mathrm{C}$. For this, the strain was activated by transferring a loopful from TSA slants into $10 \mathrm{ml}$ of tryptone soy broth without dextrose and incubating at $37^{\circ} \mathrm{C}$ for $18 \mathrm{~h}$.

In the case of $5.7 \% \mathrm{NaCl}, 100 \mu \mathrm{l}$ of the 18 -h culture, after appropriate serial decimal dilutions in one-quarter-strength Ringer's solution, was surface plated on $14 \mathrm{ml}$ TSA ( $\mathrm{NaCl}$ supplemented) solidified in a $90 \mathrm{~mm}$ Petri dish. The inoculated agar was left to dry in a biological safety cabinet for $10 \mathrm{~min}$ and, then, a disc (of $22 \mathrm{~mm}$ diameter) was removed with a scalpel, inverted, placed in a glass bottom dish ( $0.17 \mathrm{~mm}$ thickness; WillCo Wells BV, Amsterdam, The Netherlands) and led for microscopic observation. Appropriate amount of gelatin solution $5 \% \mathrm{w} / \mathrm{w}$ (Gelatin from porcine skin, Sigma-Aldrich, United States of America) containing $300 \mu$ Propidium Iodide (PI; $1.0 \mathrm{mg} / \mathrm{ml}$ in water - filter sterilized, Sigma-Aldrich, Hannover, Germany) and sodium chloride was added with care to fully cover the sample. Appropriate amount of sodium chloride was added in the gelatin solution to avoid the reduction of the final concentration of $\mathrm{NaCl}$ faced by the cells of the pathogen. Three independent experiments were conducted in order to collect data for approximately 400 cells.

In the case of $5.1 \% \mathrm{NaCl}, 100 \mu \mathrm{l}$ of the 18 -h culture, after appropriate serial decimal dilutions in one-quarter-strength Ringer's solution, was surface plated on $14 \mathrm{ml}$ TSA (no $\mathrm{NaCl}$ supplemented) solidified in a $90 \mathrm{~mm}$ Petri dish. The inoculated agar was left to dry in a biological 

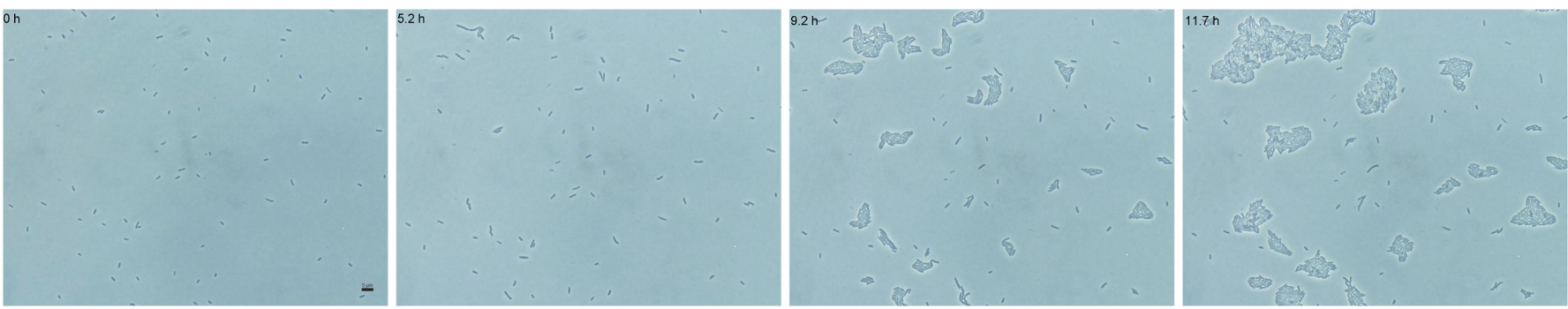

Fig. 1. Representative time lapse microscopy (phase contrast) image sequence of the growth behavior of Salmonella enterica ser. Agona single cells over time on tryptone soy agar with a final concentration of $3.5 \% \mathrm{NaCl}$ at $27^{\circ} \mathrm{C}$.

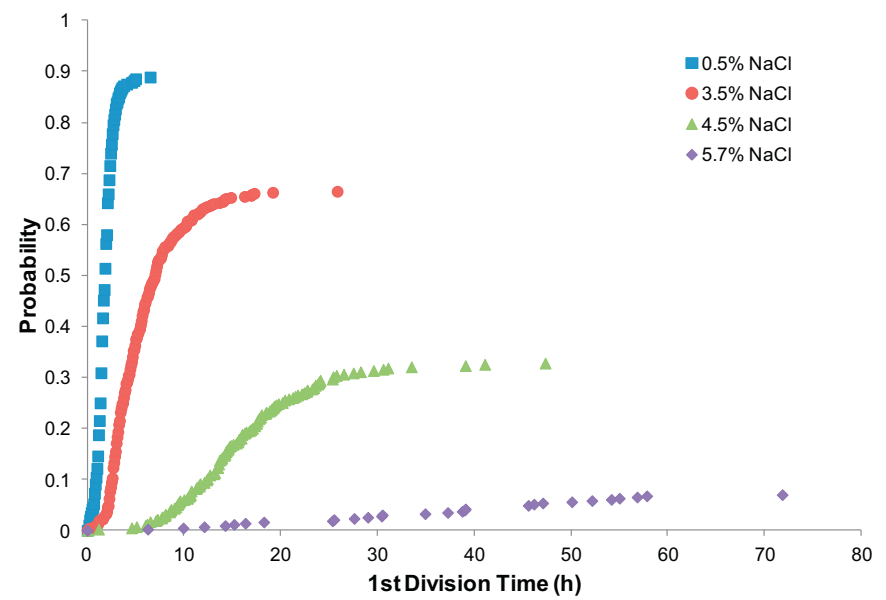

Fig. 2. Cumulative Probability Distribution (CPD) of the first division time of Salmonella enterica ser. Agona individual cells growing on TSA with different concentrations of $\mathrm{NaCl}$. The maximum probability values for each curve indicate the percentage of cells able to divide.

safety cabinet for $10 \mathrm{~min}$ and, then, a disc (of $22 \mathrm{~mm}$ diameter) was removed, inverted, placed in a glass bottom dish and led for microscopic observation. The formation of micro-colonies originating from individual cells was monitored while the sample was maintained under optimum growth conditions $\left(27^{\circ} \mathrm{C}, 95 \% \mathrm{RH}\right)$ till the formation of 2 dimensional micro-colonies consisting of approximately 30 cells. After the formation of micro-colonies, appropriate amount of gelatin solution $(5 \% \mathrm{w} / \mathrm{w})$ containing PI and sodium chloride, to reach the desired final concentration of $5.1 \%$, was added.

Individual cell growth and inactivation were monitored using an inverted confocal laser scanning microscope (TCS - SP5 II; Leica, Heidelberg, Germany) equipped with a SuperZ Galvo stage. The temperature and relative humidity were controlled using Cube 2 and Box for Leica as well as a semi-open stage top incubator for Leica SuperZ Galvo stage rotating insert and condenser. Microbial behavior (division and inactivation) was monitored using Differential Interference Contrast (DIC) and fluorescence mode simultaneously. Fluorescence of the cells was excited with the $488 \mathrm{~nm}$ argon laser line, while samples were observed with a $63 \times$ oil immersion objective. A sequence of frames for the selected field of view with time was obtained, allowing the monitoring of each cell behavior through time-lapse video. Time lapse observations were performed with Live Data Mode option. Images of the selected field of view were acquired every 5 min using Best Focus tool (Contrast based method) with $0.2 \mu \mathrm{m}$ step size in $\mathrm{z}$ axis. The high quality of the images allowed the monitoring of division times and the number of cells in the micro-colonies.

Propidium iodide is a fluorescent dye that binds to bacterial nucleic acids and is widely used as viability indicator. Based on membrane integrity, PI is permeant only in cells with compromised cell membrane, enabling the discrimination between dead and alive cells (Berney et al.,
Table 1

Statistics of the first and second division time of Salmonella enterica ser. Agona individual cells growing on TSA with different concentrations of $\mathrm{NaCl}$.

\begin{tabular}{ccccc}
\hline & \multicolumn{4}{c}{ \%NaCl } \\
\cline { 2 - 5 } & 0.5 & 3.5 & 4.5 & 5.7 \\
\hline $\begin{array}{c}\text { Number of cells tested } \\
\text { Number of cells divided }\end{array}$ & 288 & 496 & 415 & 435 \\
& 256 & 330 & 136 & 30 \\
\hline Cells able to divide (\%) & 88.9 & 66.5 & 32.8 & 7.0 \\
\hline & & 1 st division time (h) \\
\hline Mean & 1.80 & 5.48 & 16.2 & 35.9 \\
Median & 1.67 & 4.67 & 14.7 & 38.0 \\
Mode & 1.50 & 2.67 & 13.5 & 30.0 \\
Standard deviation & 0.84 & 3.45 & 7.26 & 16.6 \\
\hline & & 2 st division time (h) & \\
\hline Mean & 1.04 & 1.49 & 3.07 & 13.1 \\
Median & 1.00 & 1.25 & 2.75 & 9.50 \\
Mode & 0.75 & 1.25 & 2.00 & 3.2 \\
Standard deviation & 0.35 & 1.10 & 1.98 & 11.7 \\
\hline
\end{tabular}

2007; Stiefel et al., 2015). In a previous study of ours, an image analysis pipeline (BaSCA, Balomenos et al., 2017) was used for translating the coverage of the cells with PI into quantitative data of individual cells inactivation times. Briefly, this methodology enabled the extraction of the cells' contour and the average fluorescence inside the mask of the cell and, correspondingly, the PI coverage percentage or in other words the percentage of the cell surface covered with fluorescent pixels were measured. During exposure, the PI coverage for each cell increased with time in such a way that can be described by a sigmoidal model. After fitting the modified Gompertz equation (Zwietering et al., 1990) to PI coverage data for each single cell with time, the lag phase duration was obtained as the individual cell time of inactivation. It has been demonstrated (Gougouli and Koutsoumanis, 2012) that the $6.6 \%$ of the cell surface is covered with PI at the time that corresponds to the geometrical lag time. This low level of coverage corresponding to cell death, which in most of the times coincides with the visual identification of "color" change of the cells, was found to be in accordance with the results of a calibration procedure where the percentage of the population reduction (plating method) was related to the fraction of PI covered cells (microscopic method). Based on the above, in the present study, cell surface coverage with PI, corresponding to compromised membrane and cell death, was based on visual inspection of the sequence of images. Data about the fraction of dead and alive cells as well as of the time of inactivation were obtained.

\subsection{Study of behavior at population level}

The kinetic behavior of the pathogen was studied on solid laboratory medium (TSA) in the presence of various concentrations of sodium 

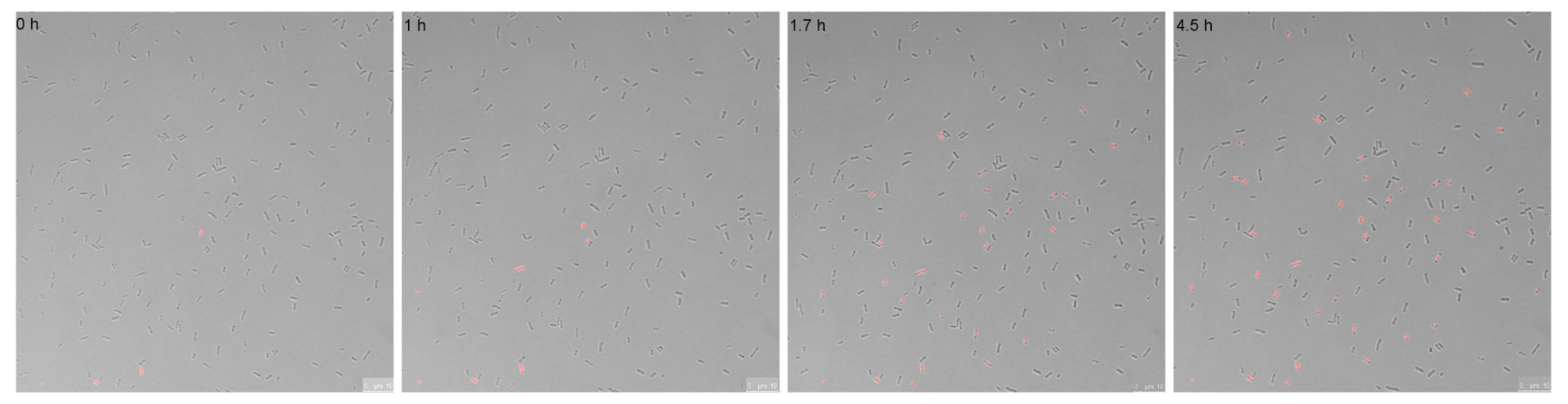

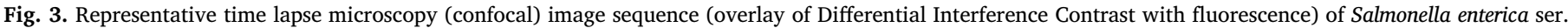

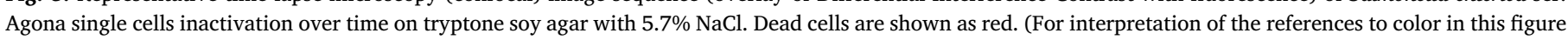
legend, the reader is referred to the web version of this article.)

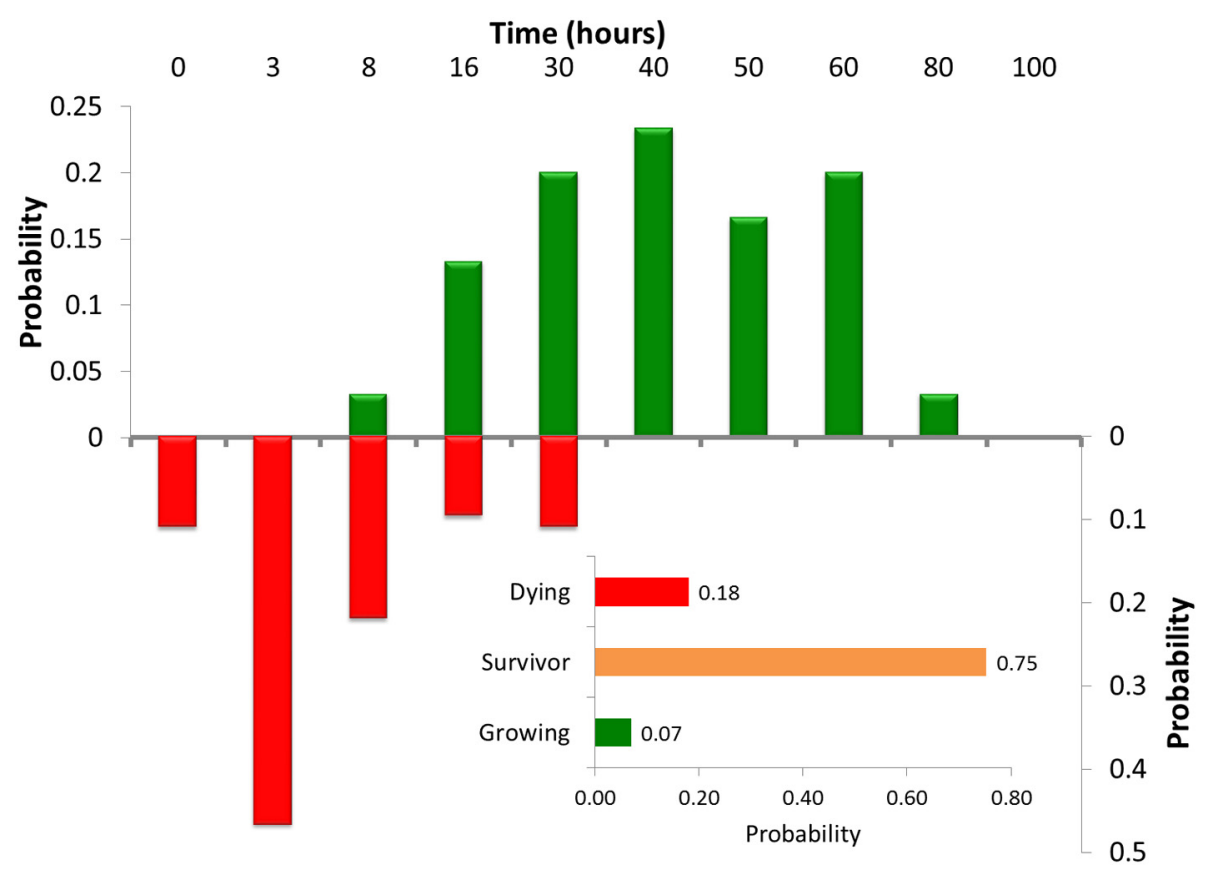

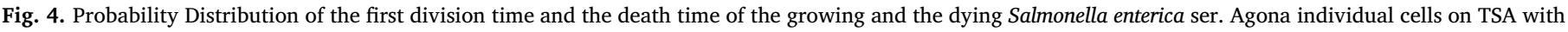
$5.7 \% \mathrm{NaCl}$. The inner graph shows the probability of the growing, surviving and dying cells at the same conditions.

chloride $(0.5 \%, 3.5 \%, 5.7 \%, 6.75 \%$ and $10 \% \mathrm{w} / \mathrm{w})$. For this, the strain was activated as described previously and $100 \mu \mathrm{l}$ of the 18 -h culture, after appropriate serial decimal dilutions in one-quarter-strength Ringer's solution, with a final population of $10^{4} \mathrm{cfu}$, was surfaced plated on TSA plates containing the appropriate amount of $\mathrm{NaCl}$. The samples were covered with parafilm to avoid water evaporation and stored under isothermal conditions at $27^{\circ} \mathrm{C}$ in high precision incubators ( $\pm 0.1^{\circ} \mathrm{C}$ ) for a total duration ranging from 1 to 7 days depending on the sodium chloride concentration.

At regular time intervals and before the formation of visible colonies, two plates for each $\mathrm{NaCl}$ concentration were analyzed. For each sample, the agar was aseptically removed and transferred into a plastic stomacher bag (Sterile bags for Bag Mixer 400) and a known volume of diluent (Ringer's solution) was added. The sample was subsequently homogenized by mixing twice for $120 \mathrm{~s}$ in a stomacher (BagMixer 400, Interscience, France). For the enumeration of the microorganism, $0.1 \mathrm{ml}$ of appropriate serial decimal dilution of the homogenate was surface plated on TSA and incubated at $37{ }^{\circ} \mathrm{C}$ for $72 \mathrm{~h}$.

\subsection{Simulations analysis}

In order to investigate the effect of coexistence of subpopulations with different behavior on total population dynamics, simulation analysis was performed using Microsoft Excel. A basic assumption that, under given environmental conditions, there are three (sub) populations of cells with different behavior was made. For the first subpopulation, all the cells are dividing and the population increases at a known growth rate without lag. The second subpopulation consists of cells that are able to survive and the concentration remains constant over the time while all the cells, in the third subpopulation, are dying and the population is reduced at a certain rate. For the predictions of population evolution the primary model of Baranyi and Roberts (1994) was used. Given the above, the evolution of a total population (10 cells) with time was estimated following certain scenarios about the number of the growing, surviving and dying cells constituting the total population. For several time points, the resultant (sum) of the 'momentary' concentrations of each subpopulation was estimated. The cells belonging to each subpopulation retained the same response (growth, survival or inactivation) over time.

\section{Results and discussion}

In the first part of the study an automated time-lapse microscopy (phase contrast) method was used to monitor the division of a total of 


\section{Subpopulations}

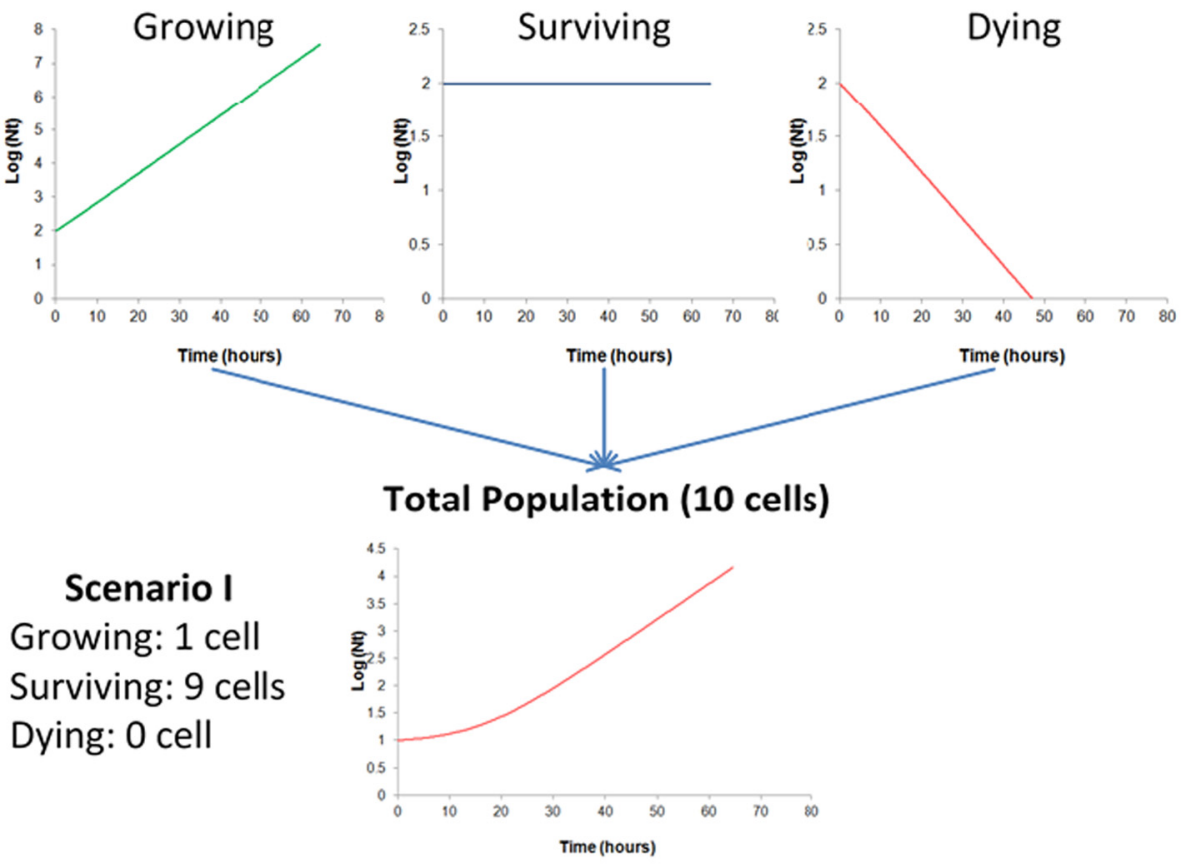

\section{Scenario II \\ Growing: 0 cell \\ Surviving: 2 cells \\ Dying: 8 cells}

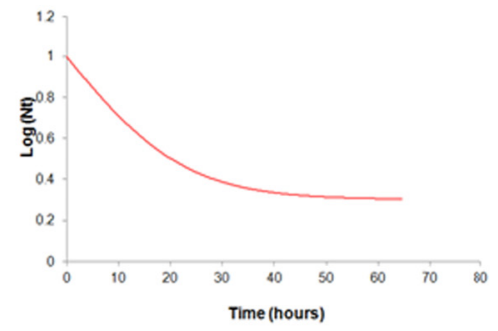

\section{Scenario III \\ Growing: 1 cell \\ Surviving: 1 cell \\ Dying: 8 cells}

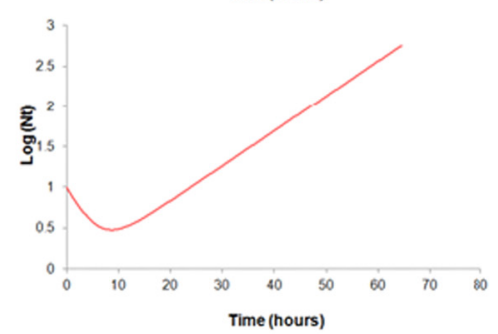

Fig. 5. Simulation scenarios for the behavior of a microbial population consisting of 10 cells in total with different fractions belonging to a growing, surviving or dying subpopulation.

1635 Salmonella cells on TSA with $0.5,3.5,4.5$ and 5.7\% NaCl. Fig. 1 shows a representative time lapse image sequence of Salmonella single cells division and colony formation over time on TSA with a final concentration of $3.5 \% \mathrm{NaCl}$ (SI Movie 1). The effect of $\mathrm{NaCl}$ on the Cumulative Probability Distribution (CPD) of the first division time of Salmonella individual cells is presented in Fig. 2. The results showed a highly heterogeneous behavior even at $0.5 \%$ of sodium chloride. As $\mathrm{NaCl}$ concentration increased, the distribution of the first division time was shifted to higher values and became wider. The mean first division time increased from $1.8 \mathrm{~h}$ at $0.5 \% \mathrm{NaCl}$ to $5.48 \mathrm{~h}, 16.2 \mathrm{~h}$, and $35.9 \mathrm{~h}$ at $3.5 \%, 4.5 \%$ and $5.7 \% \mathrm{NaCl}$, respectively. This is in agreement to previous single cell studies reporting longer and more scattered lag times as conditions move away from the optimum (Guillier et al., 2005; Guillier and Augustin, 2006; Metris et al., 2003). Table 1 presents the statistics for both first and second division times. The time to second division, which does not include the lag time, was noticeably shorter compared to the first division for all tested concentrations of $\mathrm{NaCl}$. This confirms the findings of Koutsoumanis and Lianou (2013), Metris et al. (2005) and Pin and Baranyi (2006) who reported the same trend for the generation times of bacterial cells. Despite this difference, the effect of $\mathrm{NaCl}$ on the first and second division time was similar (Table 1).

The concentration of $\mathrm{NaCl}$ in the growth medium also affected the ability of the cells to divide. The percentage of cells able to divide decreased from $88.9 \%$ at $0.5 \% \mathrm{NaCl}$ to $66.5 \%, 32.8 \%$, and $6.9 \%$ at $3.5 \%$, $4.5 \%$ and $5.7 \% \mathrm{NaCl}$, respectively. As it can be deduced from the above, even under optimal conditions $(0.5 \%$ of $\mathrm{NaCl})$, there are a few cells not able to divide. This has been also reported elsewhere (Koutsoumanis and Lianou, 2013) and it could be speculated that these cells have already died at the pre-inoculation environment (stationary phase). In this respect, it is expected that if exponential phase cells were studied, the percentage of dead cells would be lower. The effect of the osmotic stress on the ability of bacterial cells to initiate growth has been previously found for Salmonella Enteritidis and Listeria monocytogenes. Aguirre and Koutsoumanis (2016) and Koutsoumanis (2008) reported 


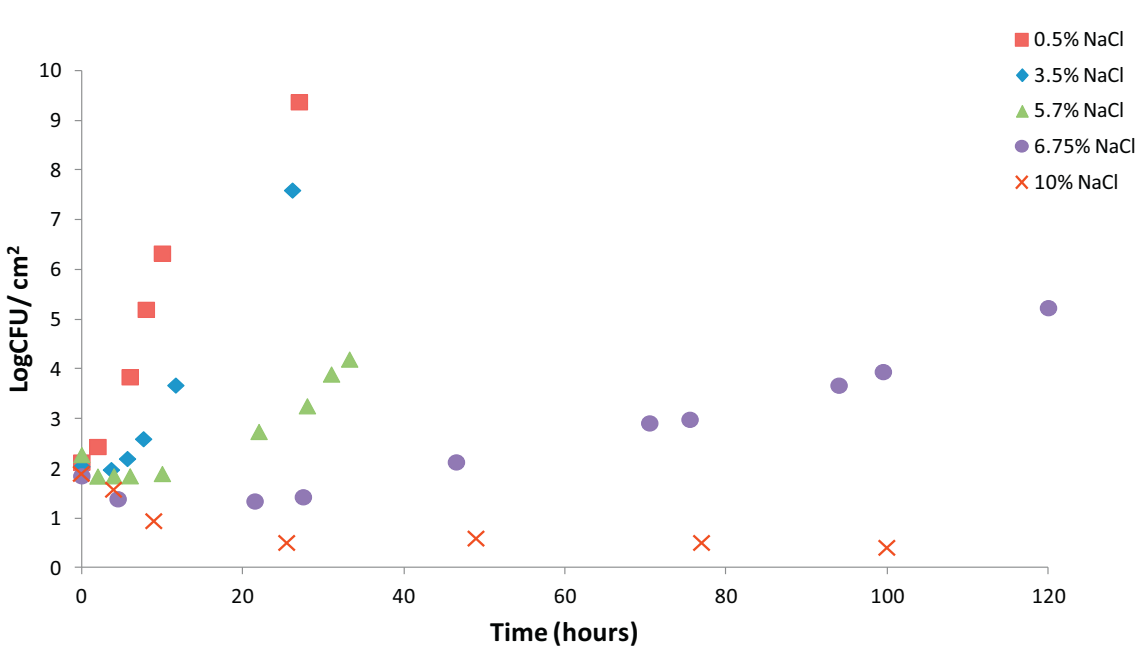

Fig. 6. Behavior of Salmonella enterica ser. Agona populations on TSA with different concentrations of $\mathrm{NaCl}$.
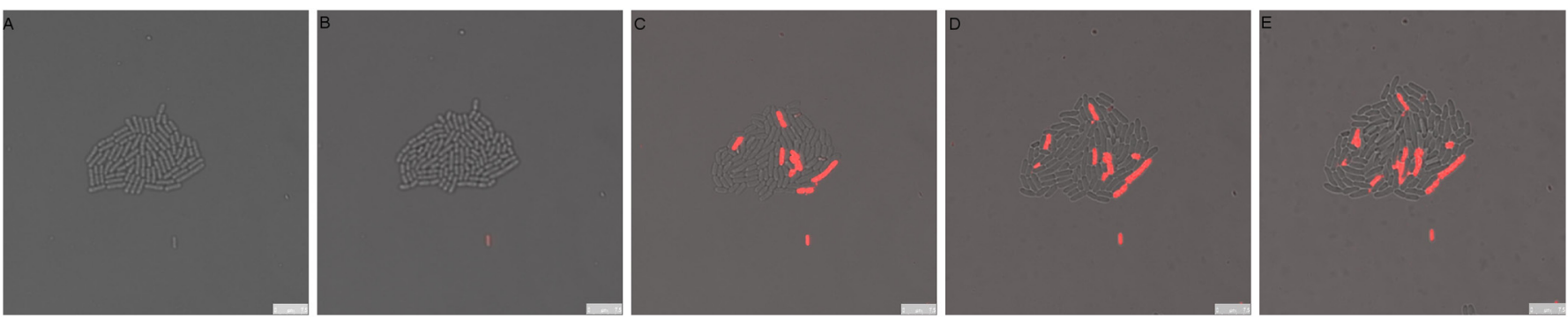

Fig. 7. Time lapse microscopy (confocal) image sequence (overlay of Differential Interference Contrast with fluorescence) of Salmonella enterica ser. Agona single cells behavior in a micro-colony on tryptone soy agar over time at $27^{\circ} \mathrm{C}$. Image A before the addition of $\mathrm{NaCl}$ and images $\mathrm{B}, \mathrm{C}, \mathrm{D}$ and $\mathrm{E}$-in the presence of $5.1 \% \mathrm{NaCl}$. Dead cells are shown as red. (For interpretation of the references to color in this figure legend, the reader is referred to the web version of this article.)

that as $\mathrm{NaCl}$ concentration increases, an increasing number of bacterial cells in the population are not able to grow. It has to be stated that in this study (3.5\%, $4.5 \%$ and $5.7 \% \mathrm{NaCl})$, among the non-dividing cells of the population, there was a part showing filamentous phenotype with an unusual increase of cell length, which has been attributed to the low water activity of the medium (Mattick et al., 2000; Pratt et al., 2012) as well as a fraction of the population that was lysed before division, a phenomenon that can be related to bacterial suicide systems (Mutschler et al., 2011).

The ability of bacteria to grow at high salt conditions is related to the intracellular accumulation of compatible solutes which act as osmolytes reducing the loss of intracellular water by osmosis (Wood et al., 2001). The concentration of these solutes in the cell is one of the main factors dictating the initiation of growth under osmotic stress. Thus, the effect of $\mathrm{NaCl}$ on growth initiation could be related to the variability in the solute pools of individual cells in the inoculum or/and in the expression of genes responsible for solute synthesis or transport mechanisms from the environment. There are several studies demonstrating that the levels of the stress response factor RpoS impacts the lag phase and the growth behavior of Salmonella cells under suboptimal hyperosmotic stress conditions (Shiroda et al., 2014). Therefore, it can be expected that this heterogeneity on the molecular level state of each cell can categorize them into several fractions such as cells able to divide, cells not able to divide that are found out of their boundary for growth and just survive, cells undergone a phenotypic switch to other states (like dormancy) where growth arrest occurs (Ayrapetyan et al., 2018) and cells susceptible to inactivation.

Taking into account the results and the above consideration the question that rose is whether the cells which are not able to divide belong to non-growing fractions or they are dead. This discrimination was not possible with the phase contrast microscopic method used in the first part. Thus, in the second part of the study the viability of Salmonella cells was studied in the presence of $5.7 \%$ sodium chloride and propidium iodide, through the repeatedly collection of images of the same field of view at distinct time intervals, using a confocal laser scanning microscope. Propidium iodide is a small fluorescent molecule that can discriminate dead and alive cells based on their membrane integrity independently of the mechanism of inactivation (Crowley et al., 2016). Fig. 3 illustrates a representative sequence of confocal micrographs of Salmonella enterica ser. Agona single cells exposed to $5.7 \% \mathrm{NaCl}$ over time, with dead cells shown in red (SI Movie 2). The results showed that 74 cells out of 406 tested (18\%) died during exposure to $5.7 \% \mathrm{NaCl}$. For these cells, the time to inactivation ranged between 0 and $23.14 \mathrm{~h}$ with mean value of $5.03 \mathrm{~h}$ and standard deviation of $6.70 \mathrm{~h}$.

The overall combination of the results allowed for the quantification of the different subpopulations of Salmonella exposed to $5.7 \% \mathrm{NaCl}$ (Fig. 4). As shown in Fig. 4 growth, survival and death of Salmonella cells can occur simultaneously under osmotic stress. It has to be stressed that, as the conditions diverge from the optimal, the heterogeneity of single cell behavior is more intense and can be manifested as the coexistence of the three different behavioral responses. Therefore, the importance of this trimodal behavior becomes evident since the different subpopulations can define the resultant under given environmental conditions. In order to investigate the effect of the above trimodal behavior of individual cells on the dynamics of the whole population, simulation analysis can be performed. Fig. 5 presents 3 indicative simulation scenarios of a microbial population consisting of 10 cells in total with different fractions belonging to the growing, surviving or dying subpopulation. In the first scenario the population consists of 9 surviving cells and 1 growing. In this case, the total population presents a lag phase although the growing cell grows without a 
lag. This behavior has been extensively discussed by Koutsoumanis (2008) who named this additional growth delay as "pseudo-lag" to differentiate it from the physiological lag. The population in the second scenario includes 8 dying and 2 surviving cells leading to the classical inactivation curve with a tail. The third scenario involves the presence of three subpopulations, within the total population of 10 cells, consisting of 8 dying cells, 1 growing and 1 surviving cell. In this case, the total population curve exhibits an initial decrease followed by exponential growth, a behavior previously termed as "Phoenix phenomenon" (Collee et al., 1961; Shoemaker and Pierson, 1976).

In order to validate the above simulation findings, the kinetic behavior of Salmonella populations was studied on solid laboratory medium (TSA) in the presence of various concentrations of sodium chloride $(0.5 \%, 3.5 \%, 5.7 \%, 6.75 \%$ and $10 \% \mathrm{w} / \mathrm{w})$. As shown in Fig. 6, the observed growth of Salmonella was in agreement with the simulation results. At optimum conditions $(0.5 \% \mathrm{NaCl})$ the population grew exponentially indicating that the majority cells are able to grow. In the case of $3.5 \% \mathrm{NaCl}$ a lag phase was observed which can be a result of both physiological lag and pseudo-lag (Koutsoumanis, 2008) as described in scenario I. At $5.7 \%$ and $6.75 \% \mathrm{NaCl}$ the "Phoenix" phenomenon was observed with an initial decline of the population followed by exponential growth. This is agreement with the results of simulation scenario III in which growth, survival and death of cells occur simultaneously. The case of $10 \% \mathrm{NaCl}$ confirms the results of simulation scenario II in which the presence of a dying and a surviving subpopulation leads to an inactivation curve with a tail.

The initial decline of the population counts followed by growth was also reported by Zhou et al. (2011) who attributed this population behavior to the suitability of the cells for the new environment with low water activity and the adaptation work that cells have to go through. However, these considerations were made for the whole population without studying the behavior at the single cell level. In the present study, the "Phoenix" phenomenon was also studied using time lapse microscopy. A growing colony of Salmonella was exposed to $5.1 \% \mathrm{NaCl}$ and the behavior of the individual cells within the colony was monitored over time. As presented in the time series images in Fig. 7 (SI Movie 3), after exposure to the osmotic stress some cells died, others continued to divide while the rest survived without dividing.

In conclusion, the results of the present study describe the behavior of Salmonella cells under osmotic stress conditions. During exposure at a moderate osmotic stress two subpopulations, one growing and one surviving, are present leading to a delay in the growth of the total population. Under more severe osmotic stress three subpopulations are observed. In this case, growth, survival and death of cells occur simultaneously leading to a total population behavior known as "Phoenix" phenomenon. The above findings show the high heterogeneity of individual cell responses and the complexity in the behavior of microbial populations at conditions approaching the boundaries of growth. It needs to be noted that such conditions are not rare in foods. For many food products the conditions are close to the growth/no growth interface due to the presence of one or more inhibitory factors such as refrigeration temperatures, low $\mathrm{pH}$ and aw, presence of preservatives etc. (Angelidis and Koutsoumanis, 2006; Koutsoumanis and Angelidis, 2007). Individual cell approaches can lead to more accurate predictions for such products and, overall, improve the performance of predictive food microbiology.

Supplementary data to this article can be found online at https:// doi.org/10.1016/j.ijfoodmicro.2018.07.012.

\section{Declarations of interest}

None.

\section{References}

Aguirre, J.S., Koutsoumanis, K.P., 2016. Towards lag phase of microbial populations at growth-limiting conditions: the role of the variability in the growth limits of individual cells. Int. J. Food Microbiol. 224, 1-6.

Angelidis, A.S., Koutsoumanis, K., 2006. Prevalence and concentration of Listeria monocytogenes in sliced ready-to-eat meat products in the Hellenic retail market. J. Food Prot. 69, 938-942.

Avery, S.V., 2006. Microbial cell individuality and the underlying sources of heterogeneity. Nat. Rev. Microbiol. 4, 577-587.

Ayrapetyan, M., Williams, T.C., Oliver, J.D., 2018. Bridging the gap between viable but non-culturable and antibiotic persistent bacteria. Trends Microbiol. 23, 7-13.

Balomenos, A.D., Tsakanikas, P., Aspridou, Z., Tampakaki, A.P., Koutsoumanis, K.P., Manolakos, E.S., 2017. Image analysis driven single-cell analytics for systems microbiology. BMC Syst. Biol. 11, 43.

Baranyi, J., Roberts, T.A., 1994. A dynamic approach to predicting bacterial growth in food. Int. J. Food Microbiol. 23, 277-294.

Berney, M., Hammes, F., Bosshard, F., Weilenmann, H.-U., Egli, T., 2007. Assessment and interpretation of bacterial viability by using the LIVE/DEAD BacLight kit in combination with flow cytometry. Appl. Environ. Microbiol. 73, 3283-3290.

Collee, J.G., Knowlden, J.A., Hobbs, B.C., 1961. Studies on the growth, sporulation and carriage of Clostridium welchii with special reference to food poisoning strains. J. Appl. Bacteriol. 24, 326-339.

Crowley, L.C., Scott, A.P., Marfell, B.J., Boughaba, J.A., Chojnowski, G., Waterhouse, N.J., 2016. Measuring cell death by propidium iodide uptake and flow cytometry. Cold Spring Harb. Protoc 87163.

Elfwing, A., LeMarc, Y., Baranyi, J., Ballagi, A., 2004. Observing growth and division of large numbers of individual bacteria by image analysis. Appl. Environ. Microbiol. 70, 675-678.

Gougouli, M., Koutsoumanis, K.P., 2012. Modeling germination of fungal spores at constant and fluctuating temperature conditions. Int. J. Food Microbiol. 152, 153-161.

Guillier, L., Augustin, J.-C., 2006. Modelling the individual cell lag time distributions of Listeria monocytogenes as a function of the physiological state and the growth conditions. Int. J. Food Microbiol. 111, 241-251.

Guillier, L., Pardon, P., Augustin, J.-C., 2005. Influence of stress on individual lag time distributions of Listeria monocytogenes. Appl. Environ. Microbiol. 71, 2940-2948.

Koutsoumanis, K., 2008. A study on the variability in the growth limits of individual cells and its effect on the behavior of microbial populations. Int. J. Food Microbiol. 128, $116-121$.

Koutsoumanis, K., Angelidis, A.S., 2007. Probabilistic modeling approach for evaluating the compliance of Ready-To-Eat doods with new European Union safety criteria for Listeria monocytogenes. Appl. Environ. Microbiol. 73, 4996-5004.

Koutsoumanis, K.P., Aspridou, Z., 2016. Moving towards a risk-based food safety management. Curr. Opin. Food Sci. 12, 36-41.

Koutsoumanis, K.P., Lianou, A., 2013. Stochasticity in colonial growth dynamics of individual bacterial cells. Appl. Environ. Microbiol. 79, 2294-2301.

Koutsoumanis, K.P., Lianou, A., Gougouli, M., 2016. Last developments in foodborne pathogens modeling. Curr. Opin. Food Sci. 8, 89-98.

Mattick, K.L., Jørgensen, F., Legan, J.D., Cole, M.B., Humphrey, T.J., Porter, J., 2000. Survival and filamentation of Salmonella enterica serovar Enteritidis PT4 and Salmonella enterica serovar Typhimurium DT104 at low water activity. Appl. Environ. Microbiol. 66, 1274-1279.

Mellefont, L.A., McMeekin, T.A., Ross, T., 2005. Viable count estimates of lag time responses for Salmonella typhimurium M48 subjected to abrupt osmotic shifts. Int. J. Food Microbiol. 105, 399-410.

Metris, A., George, S.M., Peck, M.W., Baranyi, J., 2003. Distribution of turbidity detection times produced by single cell-generated bacterial populations. J. Microbiol. Methods $55,821-827$.

Metris, A., Le Marc, Y., Elfwing, A., Ballagi, A., Baranyi, J., 2005. Modelling the variability of lag times and the first generation times of single cells of E. coli. Int. J. Food Microbiol. 100, 13-19.

Mutschler, H., Gebhardt, M., Shoeman, R.L., Meinhart, A., 2011. A novel mechanism of programmed cell death in bacteria by toxin-antitoxin systems corrupts peptidoglycan synthesis. PLoS Biol. 9.

Pin, C., Baranyi, J., 2006. Kinetics of single cells: observation and modeling of a stochastic process. Appl. Environ. Microbiol. 72, 2163-2169.

Pratt, Z.L., Chen, B., Czuprynski, C.J., Wong, A.C.L., Kaspar, C.W., 2012. Characterization of osmotically induced filaments of Salmonella enterica. Appl. Environ. Microbiol. 78, 6704-6713.

Shiroda, M., Pratt, Z.L., Döpfer, D., Wong, A.C.L., Kaspar, C.W., 2014. RpoS impacts the lag phase of Salmonella enterica during osmotic stress. FEMS Microbiol. Lett. 357.

Shoemaker, S.P., Pierson, M.D., 1976. "Phoenix phenomenon" in the growth of Clostridium perfringens. Appl. Environ. Microbiol. 32, 803-807.

Stiefel, P., Schmidt-Emrich, S., Maniura-Weber, K., Ren, Q., 2015. Critical aspects of using bacterial cell viability assays with the fluorophores SYTO9 and propidium iodide. BMC Microbiol. 15, 36.

Wood, J.M., Bremer, E., Csonka, L.N., Kraemer, R., Poolman, B., van der Heide, T., Smith, L.T., 2001. Osmosensing and osmoregulatory compatible solute accumulation by bacteria. Comp. Biochem. Physiol. A Mol. Integr. Physiol. 130, 437-460.

Zhou, K., George, S.M., Métris, A., Li, P.L., Baranyi, J., 2011. Lag phase of Salmonella enterica under osmotic stress conditions. Appl. Environ. Microbiol. 77, 1758-1762.

Zwietering, M.H., Jongenburger, I., Rombouts, F.M., Van't Riet, K., 1990. Modeling of the bacterial growth curve. Appl. Environ. Microbiol. 56. 